\title{
Taiwanese Mothers' Motivations for Teaching English to Their Young Children at Home
}

\author{
Yi-Chen Lan* \\ Jane Torr \\ Sheila Degotardi \\ Macquarie University, Australia
}

\begin{abstract}
Research has shown that mothers' attitudes towards early English language and literacy learning are important for children's English language development. Some researchers have indicated that in Taiwan most parents have a positive attitude towards English instruction and are motivated to teach English at home to their preschoolers. There is, however, little current data available to explain the motivations behind such parents' decisions to teach English to their child in the home before the commencement of formal schooling. We conducted a thematic analysis of the written survey responses of 263 Taiwanese mothers who explained why they taught their preschool children English at home. The findings indicate that English is highly valued for children's school readiness, future career opportunities, and because of its status as a global language. The mothers' motivations for teaching English include the desire to cultivate the child's interest, a belief in 'the earlier the better" for second language learning, and a belief in the need to review and practice English. These findings have the potential to inform educational policies and implementation strategies, as they can reveal whether mothers' motivations align with national priorities for English language education.
\end{abstract}

Key words : early childhood, English teaching, maternal motivation, Taiwan

In response to the widespread status of English as a global language, the Taiwanese government has recently implemented several language education policies designed to improve the English proficiency of the Taiwanese population (Su, 2006), for example reducing the age at which compulsory English language instruction at school commences (Wang, 2002). The government's motivations for promoting English in this way include the view that English is a global language which is essential for the international political and economic development of the country (Tseng, 2008). In a parallel move, there has been an increasing

* Corresponding Author: Yi-Chen Lan, Lecturer, Dance Department, Tainan University of Technology, No. 529, Zhongzheng Rd., YongKang District, Tainan City 71002, Taiwan. E-mail: t00105@mail.tut.edu.tw emphasis on the importance of the years prior to school for children's education and wellbeing, with western perspectives on early childhood pedagogy being introduced into early childhood services, with varying outcomes (Hsieh, 2004; Lee \& Tseng, 2008; Lin \& Tsai, 1996).

Interestingly, the Taiwanese Ministry of Education has prohibited English-only preschools and tends to prohibit "cram" schools for children under 6 years of age ("Minister defends plan for cram school limit," 2011; Yeh, 2011), despite pressure from some parents who believe "the earlier the better" for teaching English to children (Chang, 2006; Hsieh, 2006; Oladejo, 2006; Shang, Ingebritson \& Tseng, 2007; Tsai, 2001). As an alternative to these institutions, the Ministry of Education has encouraged mothers to co-learn English with 
their preschool child at home, using informal play-based methods such as picture books, songs and games, rather than formal skills-based methods (Taiwan Ministry of Education, 2004). This policy is based on two general issues. First, there are concerns that the introduction of formal English instruction to children under 6 years of age will negatively affect the development of their first language and culture (Chang, 2007; Chen, 2006; Hsieh, 2006). Secondly, there is a wish to ensure that very young children are not placed under undue pressure to perform academically (Cheung, 2002; Lu \& Chen, 2005).

Issues surrounding English language instruction are thus contentious in this social, political and educational context. However, despite concerns about potential negative outcomes of teaching English in the early years, it appears that Taiwanese mothers are taking an active role in teaching English to their pre-school children. A recent study of 466 mothers indicated that $61.4 \%$ were attempting to teach English to their child (Lan, Degotardi \& Torr, 2011). It is therefore significant to seek as much clarity as possible about the motivations of mothers who do decide to co-learn or to teach English to their children at home, and to determine whether or not these motivations are consistent with those underpinning Taiwan's policies regarding preschool English language instruction.

An understanding of parental motivations is significant for a number of reasons. To begin with, investigations of motivations provide insights into parenting behaviours, their teaching practices and their priorities for their children. Chinese parents are often characterized as highly competitive and driven by the need for their children to achieve academic success at all costs, including through English as a pathway to material prosperity. This, however, seems at odds with the previously mentioned concerns about the pressures involved in the early teaching of English (Cheung, 2002; Lu \& Chen, 2005). This research will provide empirical data from the mothers themselves to confirm or challenge some prevailing perceptions about what motivates Taiwanese mothers who teach their preschool aged children English at home prior to school.

Secondly, investigations into the motivations underlying the early teaching of English have significant implications for educational institutions. Early childhood educators in contemporary Taiwan are expected to take families' home practices and expectations into account, on the basis that "if educators can become aware of the normative attitudes of Taiwanese parents, they will be better able to establish partnerships with them" (Beckert, Strom, Strom, Yang, Huang, \& Lin, 2004, para. 6). Different motivations are likely to result in different expectations from mothers for their children's English development, including different teaching strategies and different demands on preschoolers and school systems. If schools have a better understanding of mothers' ideas and beliefs about English language education, they will be better placed to open up the channels of communication. Furthermore, when early childhood education is approached from a socio-cultural theoretical perspective, children's learning is best understood with consideration to the beliefs, priorities and activities of the learning communities that children are involved in (Hedegaard, 2012). Because parents' motivations will shape the opportunities and activities that they provide to their children, an understanding of these motivations will allow teachers to better understand the perspectives of both children and their families in respect to how they approach English learning in the school.

Thirdly, an understanding the motivations of mothers who engage in home teaching of English will potentially inform government policy in this area, especially as Taiwan moves towards the implementation of an early childhood curriculum. In order for the Taiwanese government to tailor its messages appropriately to its intended audience, it is necessary for the authorities to understand the motivations behind mothers' decisions. This will enable policy makers to inform public education programs to meet parents' expectations, or to communicate more effectively with parents if their 
expectations are not aligned with educational policy directions. For example, parents may want their young children to be taught English via the didactic methods of cram schools, as they are afraid that their children will be disadvantaged when they start school if this does not occur. By understanding the mothers' motivations, the government can communicate their educational policies more effectively to parents, reducing the likelihood of public disapproval and backlash.

The motivation to teach and learn English as a second language can be conceptualised in different ways. Two frequent distinctions that are made in the literature contrast intrinsic as opposed to extrinsic motivation, and integrative as opposed to instrumental motivation (Gardner \& Lambert, 1972).

Intrinsic motivation refers to any motivation that comes from within the individual and involves enjoyment of learning a second or foreign language for its own sake without external pressure (Brown, 2006; Wu, 2003). Extrinsic motivation refers to the situation where learners are motivated to achieve a particular goal, to benefit someone or to gain advantages such as better employment, a higher salary, or a promotion (Brown, 2006; Chen, Warden, \& Chang., 2005; Csizér \& Dörnyei, 2005; Dörnyei \& Csizér, 2005; Gardner, 2001; Warden \& Lin, 2000; Wu, 2003).

Gardner and Lambert (1972) proposed a model to measure the motivational orientations of language learners. Integrative motivation occurs when a language learner wishes "to learn more about the other [i.e. target] cultural community because he is interested in it in an open-minded way, to the point of eventually being accepted as a member of that other group" (Gardner \& Lambert, 1972, p.3). On the other hand, instrumental motivation, like extrinsic motivation, is said to occur "if the purpose of the language study reflects the more utilitarian value of linguistic achievement" (Gardner \& Lambert, 1972, p.3).

These two conceptual distinctions are frequently regarded as well matched. Chambers (1995) claimed that instrumental motivation is extrinsic; whereas integrative motivation is to a certain degree intrinsic (cited in Gao et al., 2004). However, in Taiwanese/Chinese contexts, these two distinctions may not be sufficient to capture all types of motivations driving Taiwanese/ Chinese EFL learners under the present educational system. Other types of motivation, referred to as "required motivation" (Warden \& Lin, 2000, p.540) or "Chinese Imperative" (Chen, Warden \& Chang, 2005, p.623) motivation, have been identified in the above two empirical studies conducted in Taiwan.

In Taiwan's English as a foreign language (EFL) setting, integrative or intrinsic motivation can be low since English is not part of the daily lives of most people. However, English is a compulsory subject in the school curriculum and proficiency in English is necessary to pass examinations. Both Chen et al. (2005) and Warden and Lin (2000) refer to the "Chinese Imperative" (p. 623) and the "required motivation" (p.540) respectively. They suggest that the need to score highly in examinations has been internalized within the current Chinese cultural environment and that this need plays a more important role than integrative motivation in English language learning.

Empirical studies focusing on the motivations of second language learners have mostly been conducted in a western context or based on data from university students, high school students or adults in EFL contexts. Less is known about the motivations of young foreign language learners, nor the motivations of mothers teaching English as a foreign language to their own children. Compared with some previous studies which have viewed motivation in second language acquisition as an abstract and hypothetical concept, no specific research on the motivations which drive Taiwanese mothers to teach their preschoolers English at home has been found in the literature. However, similar motivational distinctions to those described above may underpin the practices of such mothers.

This study is concerned with mothers' motivations for teaching English to their children, rather than their motivations for learning English themselves. The study reported here aims to 
Lan, Torr, \& Degotardi

determine the specific motivations leading to the mothers' actions, thus expanding on our understanding of this aspect of Taiwanese mothers' parenting practices.

\section{Method}

\section{Participants and Data Collection}

The data presented in this paper derive from a larger study which aimed to determine Taiwanese mothers' beliefs about teaching English to preschool aged children in the home context. A survey was distributed to mothers of preschool aged children, asking them to respond to statements which probed their attitudes towards prior-to-school and home English teaching, effective English teaching and learning practices, and their current practices. A section of the survey, two open-ended questions, asked mothers to state whether they were currently engaging in home English teaching activities with their young children and their reasons for doing so. We used open-ended questions to gain information because we wanted to give the respondents the freedom to bring out any motivational factors which were relevant for them. With closed questions, there is no opportunity to go back to the respondents to clarify their views. Open-ended questions place no restrictions on the types of ideas that are expressed, therefore producing more comprehensive and richer data than those that could be obtained from the closed questions
(Walter, 2010). As Creswell (2005) notes, openended questions are the best for researchers "to probe a little deeper and explore the many possibilities that individuals might create for a question" (p.364). The questions in Chinese and English are provided in Table 1 below.

One thousand one hundred and eighty questionnaires were distributed to mothers whose children attended 11 early childhood educational institutes and 2 church Sunday schools located in Tainan City or County. Of the 647 returned surveys, 466 mothers responded to at least one of the 2 open-ended questions. There were 286 mothers who clearly indicated that they were engaging in home English teaching and learning practices with their child, and 263 of these provided written responses to indicate their reasons. Since this study was focused on the qualitative analysis of mothers' motivations, we analyzed the responses of those mothers who were engaging in home English teaching and learning with their child and who chose to provide a written response explaining their reasons for doing so. These 263 responses became the data to be analysed in the present study. The hand-written responses were usually short paragraphs, ranging from a couple of words to 300 Chinese characters, or about 10 sentences. A research assistant transcribed the responses into electronic format and the first author translated these into English.

The participant mothers did not vary greatly in age, with the majority of them (approximately $85 \%$ ) aged from 31 to 39 years. In term of mothers' levels of education, their highest

Table 1

Two Open-ended Questions in Chinese and English

\begin{tabular}{ll}
\hline Q 46. in Chinese & 目前, 我教我的小孩學背英文嗎? 是 $\square \quad$ 否 $\square$ 為什麼? \\
\hline Q46. in English & Are you teaching your child English? Yes $\square$ No $\square$ Why or why not? \\
\hline $\begin{array}{l}\text { For Additional information in } \\
\text { Chinese }\end{array}$ & $\begin{array}{l}\text { 如果我們有遺漏重要部份, 或是您也想表達您對幼兒英語言 } \\
\text { 及識字發展的寶貴見解, 敬請不吕賜教, 填寫於下方欄內。 }\end{array}$ \\
\hline \multirow{2}{*}{$\begin{array}{l}\text { For Additional information in } \\
\text { English }\end{array}$} & $\begin{array}{l}\text { If we have overlooked asking you something important, or you } \\
\text { would like to express your views about young children's English } \\
\text { language and literacy development, please comment: }\end{array}$ \\
\hline
\end{tabular}


educational attainments were as follows: high school or lower (15.8\% of mothers), vocational diploma (19.2\% of mothers), bachelor degree ( $45 \%$ of mothers) and post graduate degree $(20 \%$ of mothers). They were drawn from the full range of SES backgrounds. Their children all were aged from 3.5 to 5.5 years. The participants were all located across the metropolitan area of Tainan, Taiwan.

\section{Validation of the Data}

Because of the different language structures, Chinese language cannot always be translated directly into English. It was therefore important to check the accuracy of the translations to ensure that the gist of the Chinese response had been captured in translation. The three authors (one native Chinese speaker and two native English speakers) discussed the translated meaning of each response to reach a consensus of the meaning. Furthermore, some responses in colloquial or poorly structured Chinese were given to 2 Taiwanese translators, who are both $\mathrm{PhD}$ students in English literature and linguistics, in order to clarify the meanings.

\section{Method of Analysis}

Thematic analysis (Braun \& Clarke, 2006) was used to analyse and categorise the responses. This analysis was conducted in three phases, with the authors working together to secure a degree of analytical plausibility. First, the authors discussed the responses in order to detect initial patterns and trends in the data. Once this was complete, each separate response was pasted on to a single sheet to facilitate inductive categorization. The first author then assigned a code to each response taking into account the content of the mothers' justification of her teaching practice. These initial codes were then refined in the final stage of analysis in which the constant comparison method (Corbin \& Strauss, 2008) was employed to develop and define each code and determine the themes to illustrate theoretical connections between them. In this stage, the authors discussed each response's underlying meaning, taking into account both the Chinese script and the English translation, and compared each response to previously discussed ones. In this way, definitions were derived from the data and these emerging definitions progressively facilitated the coding process and enabled the relationships between each code to become clear.

\section{Findings}

Six codes or themes emerged from the analysis of the mothers' responses to the openended questions about the most important reasons for teaching their child English at home. These codes were united under a superordinate theme which provided evidence of the mothers' belief in the value of English as a global language and one worth investing in. None of the respondents challenged this view.

From there, two main categories were identifiable in the data:

Category 1: Why it is important for their child to be proficient in English

Category 2: Why they have chosen to teach English to their child at home prior to school.

Within each category, three themes were identified, making six themes in total. Each theme expresses a motive evident in the mothers' responses for teaching English to their preschool aged child at home. We shall now discuss each theme in turn.

\section{Category 1: Why it is important for their} child to be proficient in English

Three main motivations for promoting their child's English proficiency were evident in the data, the majority of which could be described as primarily extrinsic or instrumental in nature.

The child's readiness for school. The first motivation related to the notion of school readiness. In Taiwan, English language instruction is a compulsory subject at the elementary school level. Some mothers commented that it was important for their child 


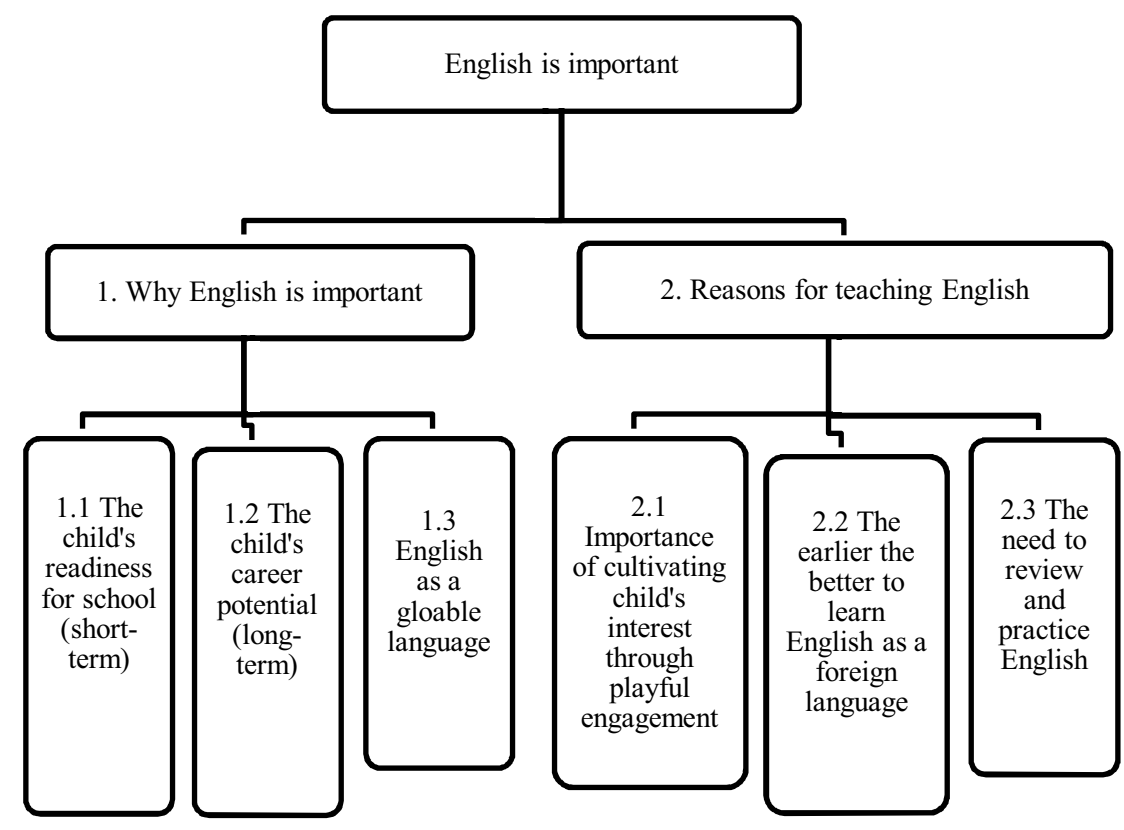

Figure 1. Themes and codes identified in the responses.

to learn English in order to prepare them for the demands of formal school learning: 對往後的正 式英文課程(學習), 應會有幫助才對。 (Mother 216) (That should be helpful for their later learning in formal instruction setting.)

The motivation appeared to be based on a concern that the child needed a head start prior to school to enable the child to cope with the demands of school.

\section{是，不想讓小孩輸在起跑點。 (Mother 634) \\ (Yes. I don't want my child left behind at the starting point.)}

The child's long term career potential. Some mothers stated that they were motivated by long term goals for their child. They expressed the view that, if their child becomes fluent in English, he or she will have better future career opportunities relative to others who are not proficient in English. Such motivations appear instrumental in nature.
不會輸在起跑點，增加在社會的競爭 力。 (Mother 609)

(Not to lose at the starting point, more competitive abilities.)

可以 help 自己多瞭解世界，同時可 幫助就業。(Mother 552)

(It can broaden your perspective and be more competitive for the future career.)

對未來會有幫助, 未來出國留學也用 得到。(Mother 514)

(Yes. It will be helpful in the future and for studying overseas.)

The status of English as a global language. The mothers strongly linked the ability to speak English to membership of the "global village". They regarded knowledge of English as an integral part of the globalization process which brings access to cultural, financial and social resources. The motivations appeared to include both integrative and instrumental elements. Mother 108 expressed 英文是世界通用的語言, 
身處地球村, 有認識與了解的必要。 (English is a global language. Living in a global village, it is necessary to learn English.)

English proficiency was seen as a vehicle for increasing their knowledge of others, indicating a general valuing of cross cultural understanding: 時勢所趨, 也可以了解他國文化。(Mother 013) (It is the trend. By the way, it is as the tool to know another culture.)

Category 2: Reasons for choosing to teach English to their child at home prior to school

The three themes above were related to mothers' motivations in wanting their child to become proficient in English. Three closely related themes emerged which described the mothers' motivations in choosing to teach their child English at home prior to the commencement of formal schooling. These themes are as follows.

It is important to cultivate the child's interest in English through playful engagement. Here many mothers expressed an awareness of the value of integrated motivation. Some mothers explained that their child had already shown an interest in learning English. The child's interest motivated the mothers to further cultivate that interest by teaching their children English songs and by reading English picture books together.

我的小朋友對英文很有興趣，也勇於 嘗試，而不排斥語言的情況下，小朋友 透過歌曲、圖畫書，特定學狛教材認識 各種語言, 我的小朋友在沒有壓力的 情況下, 反而培養出尋找知識樂趣, 當 然也包括英文程度提升！(Mother 580) (My child shows high interest in English. He learns by songs, picture books, some teaching materials. He enjoys learning in a happy way without stress and develops a habit of seeking knowledge. Of course, that includes making progress in his English ability.)

老二因為很喜歡英文，所以會教他一 些英文歌曲或單字。(Mother 049)
(My second child loves English very much so I teach him some English songs and words.)

Several mothers identified a shared interest with their child, which led to a collaborative approach to learning together. Mother 572, for example, stated 陪他一起學習，他很喜歡。

(He learns with my company and support; he loves that.) and Mother 628 said 自己喜歡而且 小孩也喜歡。(Yes. Both my child and I like English). Many mothers recognized that young children learn in different ways than older children. Mother 482 responded 不用傳統教學 万式，讓小孩在遊戲和唱這種方式熟悉第二 種語言，不排斥學習，自然而然的說或唱, 只是讓她提早接觸不同的語言。(I don't use the traditional teaching methods; instead, by playing games and singing songs, she gets familiar with the second language at an early age.)

The earlier the better to learn English as a foreign language. Many mothers were motivated by their belief that the earlier children are exposed to an additional language, the more quickly they will learn that language. Some mothers explained this in terms of early brain development, both in relation to critical periods for development and the facilitation of cognitive development:

\section{希望在她腦部發展最快吸收最快時教} 他第三語言。(Mother 046)

(I hope I teach her the third language during the rapid period of brain development.)

讓他在遊戲中學英文。中文英文對小 孩而言, 即統為語言區塊, 刺激語言區 塊與協專注力，不管何種語言都 $\mathrm{ok}_{0}$

(Mother 630)

(No matter which language he learns helps stimulate the brain language section and help for his concentration.)

Others felt that early learning would promote 
more effective L2 acquisition. Mother 272, for example, stated that 愈早接觸效果愈佳, 發音 也漂亮。(The earlier, the better. Early learning makes the pronunciation like the native speakers.).

The need to review and practice English. A final theme which emerged from the data was the motivation of some mothers to provide their child with the opportunity to practice and review the English language instruction which their child already receives from kindergarten English lessons or from an external private English coaching school. Some coaching schools expect mothers to review lessons at home with their child, and this requirement was reflected in statements like 因為課後英文的部份需要家長 協同完成作業。(Mother 438) (It is required for parents to assist child's homework.) Other mothers stated that they tried to "match" the coaching schools lessons or kindergarten homework at home for consistency in their child's learning and clearly valued their own input in their children's learning:

\section{學校教的會幫她複曶，為了讓他更熟 練。(Mother 036)}

(I help her review what she has learned at school in order that she is familiar with what has been taught.)

是，因為父母親是需要與小孩一同學 習, 否則父母親無法幫助孩子複習功課, 這樣小孩學曶效果就會較不佳。 (Mother 146)

(Yes, children need to learn things with their parents' company or parents cannot help their children to review what they have learned. Without parents' help, children's learning is less effective.)

\section{Discussion}

This study aimed to determine the specific motivations which drive Taiwanese mothers to attempt to teach their preschoolers English at home. The findings suggest that a range of motivations may underpin their decision making. One factor which emerged strongly from the data was the importance of what has been referred to as "Chinese imperative motivation" or "required motivation". This appeared to be the most significant factor driving Taiwanese mothers to engage in home teaching of English.

The term “需要” (requirement/required) appeared at least 42 times in the written survey responses. Many mothers asserted that they were teaching English at home because it is "required" by the English "cram" schools their preschool children attended, for consistency of the children's learning. The expression "requirement" in the present study, however, appears to have a slightly different meaning compared with the use of the term "requirement" described in the studies of Warden and Lin (2000) and Chen, Warden, and Chang (2005). In these latter studies, the word refers to the fact that within the Chinese cultural context, students are required to study English as it is a compulsory subject, and to pass different kinds of examinations. In the current study, when the mothers used the term "requirement", it referred to their role in providing support for their children, because they believed that parents are responsible for their children's academic success. This finding indicates that the surveyed mothers' attitudes may be similar to those found by Hadley (2003) and Wang and Tamis-LeMonda (2003), demonstrating that Taiwanese mothers valued school achievement and were willing to sacrifice their own needs to enhance their children's opportunities for academic success (Chao, 1996).

It is perhaps surprising to note that motivation which could be considered integrative or intrinsic from the point of view of the mothers themselves was only identified in a few responses. This could be seen when mothers indicated that they enjoyed teaching and learning English with their children (e.g. Mother 628). In this study, intrinsic motivation was instead associated with the mothers' attempts to promote their children's long-term interest and engagement. Many mothers sought to cultivate their child's intrinsic motivation through interesting activities, songs and games. This 
finding suggests that mothers' motivations align with those of the Taiwanese government which promotes the value of mothers teaching English to their preschool aged children in the home.

It is possible that English language learners in Taiwan might change their motivational orientation as they play out different roles in their lives. As university students become parents, their personal aspirations may change and they may focus more on the intrinsic value of learning another language, which then motivates them to become aware of interest and engagement as internal motivators for their young children's English language learning. Thus, hopefully, the absence of intrinsic motivation in the Taiwanese English as a Foreign Language environment presented in Warden and Lin's study (2000) would be mitigated by the increasing awareness of the value of intrinsic motivation for learning an additional language.

There was strong evidence that most mothers value English proficiency highly, and want to facilitate it in their children. On the one hand, mothers see a utilitarian purpose for their children to learn English. The mothers want their children to learn English for personal short-term or long-term benefits, such as to succeed in formal schooling and to be competitive when establishing their future careers. This finding is consistent with those of other studies about Taiwanese parents' attitudes towards early English language learning (Oladejo, 2006; Shang, Ingebritson \& Tseng, 2007; Tsai, 2001). This finding, moreover, appears to support the view that instrumental motivations for learning English are predominant in many Asian contexts, such as Taiwan (Warden \& Lin, 2000), Hong Kong (Lai, 1999), Japan (Yashima, 2002), China (Gao et al., 2004) and Korea (Park, \& Kwon, 2009).

In this study, the impact of globalization on mothers' motivations was emphasized. This finding has also been evident in a variety of studies of EFL contexts, where English language learners appear to acquire an identity as "world citizens" (Lamb, 2004). Bradford's (2007) study has noted that many Asian people value English as a tool for competing successfully in the international community. Bradford's participants also agreed that English is used to communicate with a variety of people from other countries and that English proficiency will increase their knowledge of other cultures (Bradford, 2007). This sounds similar to the statements of many of the mothers in this study. However, the integrative motivation evident in this study is somewhat different from the traditional concept of integrative motivation described by Gardner and Lambert (1972), where learners were highly motivated to interact with the target language community. This difference may be because, unlike the situation where L2 learners are living in a culture where they do not speak the dominant language, the Taiwanese setting is largely non-English speaking so there are limited opportunities for the actual use of English. Nevertheless, the mothers of these young learners regarded success in mastering English language as of vital importance and as one way of becoming an integral part of a worldwide community. In this way, the study is consistent with the integrative motivation identified in the studies of Lamb (2004; 2007), McKay (2003) and Warschauer (2000).

The distinctions that were made in previous motivational studies, such as those between extrinsic and intrinsic motivations, instrumental as opposed to integrative motivations, and required referred to Chinese imperative motivations, are helpful in understanding the different types of motivation driving Taiwanese mothers to teach their preschoolers English at home and in understanding why the mothers want their children to learn English prior to the commencement of formal school. This present study shows that mothers can simultaneously hold future-oriented values for their children, such as their belief in the power of globalization and the future opportunities it offers, while also caring about and providing for children's current interests, play-based learning opportunities and engagement.

An unexpected finding was the range of ways in which the word "teaching" was used in the survey, suggesting that this word has many 
nuances in Chinese. The manner in which the mothers interpreted the word "teach" appeared to vary and suggests that we need to re-examine how "teach" was defined. The common interpretation of "teach (教)" among these mothers appears to include the provision of basic knowledge, as well as interactions which will scaffold children's learning and increase the effectiveness of their teaching practices.

\section{Limitations}

The exploratory nature of this study should be acknowledged. This study focused only on mothers of children aged from 3.5 to 5.5 years in Tainan City and County. The participants may not be fully representative of the larger Taiwanese population, especially those living in rural areas and from different cultural backgrounds. Though this study provided evidence from mothers of young children about their motivations, and reasons for teaching English language to their children, the data were obtained from written survey responses. It was therefore not possible to probe further to understand more fully their motives and reasons. Furthermore, some mothers were more able to express themselves in writing than others. Despite these limitations, this study does present the first attempt to explore the mothers' motivations for home English teaching in a Chinese context.

\section{Conclusion and Directions for Future Research}

The findings of this study may be relevant to other Chinese societies such as Mainland China and Hong Kong, where issues surrounding the place of English in contemporary society are a major focus of interest and concern. In the case of Taiwan, the government is actively promoting policies aimed at improving the English proficiency of its citizenry. The more we can understand the motivations of mothers who are attempting to implement the government's policies, the more possible it will be to tailor government information and educational materials to meet the needs and desires of mothers of young children. Alternatively, if the motivations of mothers do not align with those of the Taiwanese government regarding early childhood English education, further consultation and refinement of their policies will be necessary. The limited evidence available indicates that mothers from different social and cultural backgrounds in Taiwan may have different motivations when deciding whether or not to teach English to their preschoolers. Future research may investigate whether Taiwanese mothers' educational level and their English abilities are associated with their views about English language pedagogy for young children and their use of English learning resources and practices in the home. In depth interviews of mothers would complement the findings of this study.

\section{References}

Beckert, T. E., Strom, P. S., Strom, R. D., Yang, C.-T., Huang, N.-Y., \& Lin, Y.-W. (2004). Parent expectations of young children in Taiwan. Early Childhood Research and Practice, 6(2), NA. Retrieved from http://ecrp.uiuc.edu/v6n2/beckert.html

Bradford, A. (2007). Motivational orientations in under-researched FLL Contexts: Findings from Indonesia. RELC Journal, 38(3), 302323.

Braun, V., \& Clarke, V. (2006). Using thematic analysis in psychology. Qualitative Research in Psychology, 3, 77-101.

Brown, H. D. (2006). Principles of language learning and teaching (5th ed.). New York: Pearson Education.

Chang, L.-C. (2006). A study of early childhood bilingual education and language shift: A survey to kindergarteners' parents in Tainan City. Journal of Chang Jung Christian University, 10(1), 169-187.

Chang, S.-J. (2007). 我的孩子不會講中文?! [My child cannot speak Chinese?! ] (2nd ed.). Taipei: 新手父母[Parenting Source Press].

Chao, R. K. (1996). Chinese and European American mothers' beliefs about the role of 
parenting in children's school success. Journal of Cross-Cultural Psychology, 27(4), 403-423.

Chen, J. F., Warden, C. A., \& Chang, H.-T. (2005). Motivators that do not motivate: The case of Chinese EFL learners and the influence of culture on motivation. TESOL Quarterly, 39(4), 609-633.

Chen, Y. L. (2006). The influence of kindergarten English immersion programs on children's (3-7years old) perceptions of their native language and culture: A case study. English Teaching \& Learning, 30(4), 87-109.

Cheung, H. (2002). 幼兒學習英語的時機與教 學方式 [Timing and teaching methods for young children learning English]. 成長幼教 季刊 [Healthy Growth Foundation Journal on Early Childhood Education], 49, 22-25.

Corbin, J. M., \& Strauss, A. L. (2008). Basics of qualitative research: Techniques and procedures for developing grounded theory (3rd ed.). Thousand Oaks, CA: Sage.

Creswell, J. W. (2005). Educational research: Planning, conducting, and evaluating quantitative and qualitative research (2nd ed.). Upper Saddle River, NJ: Pearson Education

Csizér, K., \& Dörnyei, Z. (2005). The internal structure of language learning motivation and its relationship with language choice and learning effort. The Modern Language Journal, 89(1), 19-36.

Dörnyei, Z., \& Csizér, K. (2005). The effects of intercultural contact and tourism on language attitudes and language learning motivation. Journal of Language and Social Psychology, 24(4), 327-357.

Gao, Y., Zhao, Y., Cheng, Y., \& Zhou, Y. (2004). Motivation types of Chinese university undergraduates. Asian Journal of English Language Teaching, 14, 45-64.

Gardner, R. C. (2001). Integrative motivation and second language acquisition. In $\mathrm{Z}$. Dörnyei \& R. Schmidt (Eds.), Motivation and second language acquisition (technical report) (pp. 1-20). Honolulu: National Foreign Language Resource Center, University of Hawaii.

Gardner, R. C., \& Lambert, W. E. (1972).
Attitudes and motivation in second-language learning. Rowley, MA: Newbury House.

Hadley, K. G. (2003). Children's word play: Resisting and accommodating Confucian values in a Taiwanese kindergarten classroom. Sociology of Education, 76(3), 193-208.

Hedegaard, M. (2012). The dynamic aspects in children's learning and development. In M. Hedagaard, A. Edwards, and M. Fleer (Eds.), Motives in children's development: Culturalhistorical approaches (pp. 9-27). New York: Cambridge University Press.

Hsieh, M.-F. (2004). Teaching practices in Taiwan's education for young children: Complexity and ambiguity of developmentally appropriate practices and/or developmentally inappropriate practices. Contemporary Issues in Early Childhood, 5, 309-329.

Hsieh, M.-F. (2006). "My mom makes me to learn English": Power, system, instruction, and quality of early childhood English language education in Taiwan. (Doctoral dissertation). Available from ProQuest Dissertations and Theses database. (UMI No. 3232577)

Lai, E. F.-K. (1999). Motivation to learn English in Hong Kong. Language, Culture \& Curriculum, 12(3), 280-284.

Lamb, M. (2004). Integrative motivation in a globalizing world. System, 32(1), 3-19.

Lamb, M. (2007). The impact of school on EFL learning motivation: An Indonesian case study. TESOL Quarterly, 41(4), 757-780.

Lan, Y.-C., Degotardi, S., \& Torr, J. (2011). Factors related to the home teaching of English language to preschool aged children: A Taiwanese study. Asia-Pacific Journal of Research in Early Childhood Education, 5(2), 27-48.

Lee, I. F., \& Tseng, C. L. (2008). Cultural conflicts of the child-centered approach to early childhood education in Taiwan. Early Years, 28(2), 183-196.

Lin, Y.-W., \& Tsai, M.-L. (1996). Culture and the kindergarten curriculum in Taiwan. Early Child Development and Care, 123(1), 157165. 
Lu, H. J., \& Chen, T. A. (2005). 由國家語言政 策評估台灣幼兒英語教育之現況發展 [An evaluation on early childhood English education in Taiwan --from the perspective of language policy]. 環球技術學院科技人文學 刊 [Journal of Science and Technology and Humanities of Transworld Institute of Technology], 2, 45-56.

McKay, S. (2003). Teaching English as an international language: The Chilean context. ELT J, 57(2), 139-148.

Minister defends plan for cram school limit. (2011, November 3). The China Post. Retrieved from http://www.chinapost.com.tw /print/321823.htm

Oladejo, J. (2006). Parents' attitudes towards bilingual education policy in Taiwan. Bilingual Research Journal, 30(1), 147-170.

Park, J.-H., \& Kwon, Y. I. (2009). Parental goals and parenting practices of upper-middle-class Korean mothers with preschool children. Journal of Early Childhood Research, 7(1), 58-75.

Shang, H.-F., Ingebritson, R., \& Tseng, C.-L. (2007). Taiwanese parental perceptions toward English learning in bilingual kindergarten. In Y.-R. Tsai, H.-F. Shang \& H. Hanreich (Eds.), Applied English education: Trends and issues (pp. 135-148). Kaohsiung County, Taiwan: I-Shou University.

Su, Y.-C. (2006). EFL teachers' perceptions of English language policy at the elementary level in Taiwan. Educational Studies, 32(3), 265-283.

Taiwan Ministry of Education. (2004). 學齡前 幼兒英語教育政策說帖 [The Brochure of Early Childhood English Education Policy] Retrieved March, 20, 2009, from http://www.ece.moe.edu.tw/document/earleng .pdf/earleng.html/

Tsai, C. H. (2001). 家長對幼兒美語學習態度 探討-- 以高雄為例 [Parents' Attitudes Towards English Learning for Their Kindergarten Children]. 碩士論文(Master's thesis), 南華大學 (Nanhua University), ChiaYi, Taiwan. Retrieved from http:// etds.ncl.edu.tw/theabs/service/detail_result.jsp
Tseng, C.-L. (2008). Understanding the desirability of English language education in Taiwan. Contemporary Issues in Early Childhood, 9(1), 83-86.

Walter, M. (Ed.). (2010). Social research methods (2nd ed.). South Melbourne, Australia: Oxford University Press.

Wang, C. (2002). Innovative teaching in foreign language context: The case of Taiwan. In S. J. Savignon (Ed.), Interpreting communicative language teaching: Contexts and concern in teacher education (pp.131-153). New Haven, CT: Yale University Press.

Wang, S., \& Tamis-Lemonda, C. S. (2003). Do child-rearing values in Taiwan and the United States reflect cultural values of collectivism and individualism? Journal of Cross-Cultural Psychology, 34(6), 629-642.

Warden, C. A., \& Lin, H.-J. (2000). Existence of integrative motivation in an Asian EFL setting. Foreign Language Annals, 33(5), 535-545.

Warschauer, M. (2000). The changing global economy and the future of English teaching. TESOL Quarterly, 34(3), 511-535.

$\mathrm{Wu}, \mathrm{X}$. (2003). Intrinsic motivation and young language learners: The impact of the classroom environment. System, 31(4), 501517.

Yashima, T. (2002). Willingness to communicate in a second language: The Japanese EFL context. The Modern Language Journal, 86(1), 54-66.

Yeh, J. (2011). MOE's proposed ban on cram schools recruiting students under 6 draws criticism, The China Post. Retrieved from http://www.chinapost.com.tw/print/321677.htm

Received February 1, 2012

Revision Received March 26, 2012 Accepted April 10, 2012 